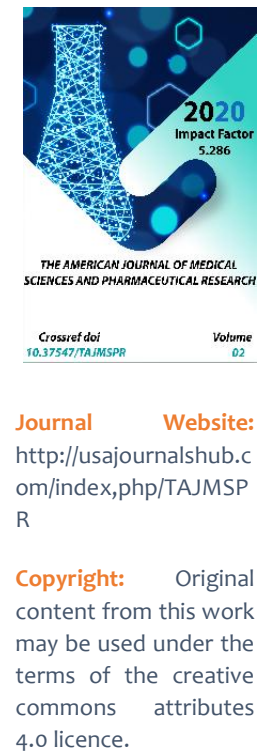

\title{
Selection And Characteristics Of The Surveyed Contingent Of Sick Adolescent Girls With Iron Deficiency
}

\author{
Shaira Atadjanova Khalilovna \\ Assistant, Department of Facultative Pediatrics and Neonatology, Andijan State Medical \\ Institute, Andijan, Uzbekistan
}

\section{ABSTRACT}

Iron deficiency anemia (IDA) is a common disease of adults and children, which is characterized by a decrease in the content of hemoglobin and erythrocytes per unit volume of blood due to deficiency of iron (ID), protein, trace elements, vitamins, with characteristic clinical and laboratory parameters $[5,7,8,10]$. Moreover, the proportion of iron deficiency anemias (IDA) among them is more than $80 \%$ of all cases of DA $[1,5,6]$.

\section{KEYWORDS}

Iron deficiency anemia, latent iron deficiency, adolescents.

\section{INTRODUCTION}

The problem of prevention, diagnosis and treatment of IDA is extremely relevant for the health care of many countries of the world, including Uzbekistan, due to its widespread prevalence [2, 3]. According to various researchers, the incidence of IDA varies from $60-80 \%$ in pregnant women, women of fertile age, including among schoolchildren - 40-50\% $[3,7,10]$. Judging by the literature data, the pathogenesis of IDA is not fully understood. So, the end result in the form of IDA can be formed due to a low depot in the body or insufficient intake of iron from food, increased consumption, due to the rapid growth and 
development of children, or microdiapedesic (through the intestines) or macro loss of iron with erythrocytes in menarche, chronic gastrointestinal diseases $[1,7,9]$. At the same time, IDA can develop due to a decrease in the iron-binding capacity of serum (sideroachristia), with a protein deficiency (protein deficiency), due to a decrease in the activity of intestinal enzymes involved in the absorption of iron and vitamins, due to congenital or acquired deficiency of intrinsic factor, not only gastric, but and the duodenum $[1,2,5]$.

\section{MATERIALS AND METHODS}

To identify iron deficiency among schoolchildren, we used the randomization method. The initial material for determining the number of schoolchildren in the city of Andijan was the list (alphabetical) of students aged 7-14 years (12000). Of this number of students, 1200 children aged 7-14 years were selected using the Brodfer table (10\% sample). According to the requirements of epidemiological studies, according to the table, all the numbers are written from left to right from row 00 and columns 1, 2, 3, 4, because, the maximum number of children is four-digit (1200), making up all numbers more than 1201 without calculation. As a result, it turned out, that the studied group includes children with a serial number (№№): 0226, 0326, 0113, 0991, 0508, etc. If any number was repeated, then we omitted the last and the list continued until we got 1200 different numbers. A fragment of the selective work is shown in Table 1.

\section{Table 1}

Fragment of a sample of the surveyed contingent of urban schoolchildren to identify iron deficiency

\begin{tabular}{|c|c|c|c|c|c|}
\hline $\begin{array}{c}\text { A series of } \\
\text { random } \\
\text { numbers }\end{array}$ & $\begin{array}{c}\text { № № } \\
\text { surveyed }\end{array}$ & $\begin{array}{c}\text { Series of } \\
\text { random } \\
\text { numbers }\end{array}$ & $\begin{array}{c}\text { № № } \\
\text { surveyed }\end{array}$ & $\begin{array}{c}\text { Series of } \\
\text { random } \\
\text { numbers }\end{array}$ & $\begin{array}{c}\text { № № } \\
\text { surveyed }\end{array}$ \\
\hline 0226 & 226 & 0739 & 739 & 0039 & 39 \\
\hline 0316 & 316 & 0531 & 531 & 1158 & 1158 \\
\hline 0113 & 113 & 0437 & 437 & 1155 & 1155 \\
\hline 0991 & 991 & 1057 & 1057 & 0214 & 214 \\
\hline 0508 & 508 & 0727 & 727 & 0505 & 505 \\
\hline 0860 & 860 & 0872 & 872 & 1083 & 1083 \\
\hline \multicolumn{7}{|c|}{ etc. total 1200 students } \\
\hline
\end{tabular}

\section{RESULTS AND DISCUSSION}

930 children aged 7-10 were surveyed, which constituted $77.5 \%$ of the selected sample of schoolchildren (1200). To establish the iron deficiency nature of anemia, we were guided by a set of laboratory studies (in more detail below), determination of serum iron in the morning, transferrin saturation coefficient with iron (CST\%), total and latent iron-binding capacity (TIBC, LVCC) of blood serum, determination of blood transferrin, etc. Indicators of iron metabolism, qualitative and quantitative indicators of peripheral blood 
were studied in the dynamics of observation and treatment - only four times (initial data by the end of the period of saturation of the body with iron, after six months and a year).
The results of the analysis of iron deficiency among urban schoolchildren are shown in Table 2.

Table 2

Frequency of iron deficiency among urban schoolchildren

\begin{tabular}{|c|c|c|c|c|c|c|c|c|c|}
\hline \multirow[b]{2}{*}{ № } & \multirow{2}{*}{$\begin{array}{c}\text { Age. } \\
\text { surveyed }\end{array}$} & \multirow[b]{2}{*}{ Gender } & \multirow{2}{*}{$\begin{array}{l}\text { Number } \\
\text { of the } \\
\text { examined }\end{array}$} & \multicolumn{2}{|c|}{ LID } & \multicolumn{2}{|c|}{ IDA } & \multicolumn{2}{|c|}{ LID+IDA } \\
\hline & & & & abs & $\%$ & abs & $\%$ & abs & $\%$ \\
\hline \multirow{4}{*}{1} & \multirow{2}{*}{ 7-10 years old } & $M$ & 232 & 44 & 19,0 & 32 & 13,8 & 76 & 32,8 \\
\hline & & $G$ & 233 & 58 & 24,9 & 70 & 30,0 & 128 & 54,9 \\
\hline & Up & - & - & \multicolumn{2}{|c|}{1,54} & \multicolumn{2}{|c|}{4,3} & \multicolumn{2}{|c|}{4,85} \\
\hline & $\mathrm{p} \varphi$ & - & - & \multicolumn{2}{|c|}{$>0,05$} & \multicolumn{2}{|c|}{$<0,001$} & \multicolumn{2}{|c|}{$<0,001$} \\
\hline \multirow{4}{*}{2} & \multirow{2}{*}{$11-14$ years old } & $M$ & 232 & 63 & 27,0 & 49 & 21,0 & 112 & 48,1 \\
\hline & & $G$ & 232 & 54 & 23,3 & 81 & 34,9 & 135 & 58,2 \\
\hline & Up & - & - & \multicolumn{2}{|c|}{0,92} & \multicolumn{2}{|c|}{3,26} & \multicolumn{2}{|c|}{2,19} \\
\hline & $\mathrm{p} \varphi$ & - & - & \multicolumn{2}{|c|}{$>0,05$} & \multicolumn{2}{|c|}{$<0,001$} & \multicolumn{2}{|c|}{$<0,0014$} \\
\hline \multirow{2}{*}{\multicolumn{2}{|c|}{ Total }} & $M$ & 465 & 107 & 23,0 & 81 & 17,4 & 188 & 40,4 \\
\hline & & $G$ & 465 & 112 & 24,1 & 151 & 32,5 & 263 & 56,6 \\
\hline & Up & - & - & \multicolumn{2}{|c|}{0,39} & \multicolumn{2}{|c|}{5,37} & \multicolumn{2}{|c|}{4,96} \\
\hline & $\mathrm{p} \varphi$ & - & - & \multicolumn{2}{|c|}{$>0,05$} & \multicolumn{2}{|c|}{$<0,001$} & \multicolumn{2}{|c|}{$<0,001$} \\
\hline
\end{tabular}

The Results of our research have shown (Table 2) that the frequency of LVH in schoolchildren, depending on their gender, did not differ statistically $(23.0 \%$ and $24.1 \%$, p> 0.0 ), their frequency also does not differ in age aspect $7-10$ years $(19.0 \%$ and $24.9 \%, p \varphi>$ 0.05 ) and $11-14$ years (27.0\% and $23.8 \%, p>$ 0.05). The distribution of LHD among schoolchildren in our studies was 235 per 1000 examined, respectively for boys and girls: 250 and 241. When comparing these data with similar work (Ganieva M.G. et al., 1991), carried out in our region for more than twenty years ago, we found that in urban children there is currently a decrease in the prevalence of LVD (235 per 1000 examined), compared with the data of the above authors (321 per 1000, IR = 4.86, $p \varphi<0.001)$.

Table 2 also shows that the frequency of IDA is significantly higher in female schoolchildren (32.5\% versus $17.4 \%$ of boys, $p<0.001$ ). This pattern is also revealed in the age aspect of 710 years (30.0\% versus $13.8 \%, p \varphi<0.001)$ and $11-$ 14 years (34.9\% versus $21.0 \%, p \varphi<0.001)$. The prevalence of IDA in our studies was 249 per 1000 examined, which is two times higher than the data of N.N. Chukanina et al. (1995): 124 per 1000 ( $I R=8.19, p \varphi<0.001)$. The total frequency of LHD and IDA in our work was 451 per 1000 examined, which does not differ significantly from those of the above authors (445 per 1000, $p \varphi>0.05$ ), but their frequency among female schoolchildren is significantly 
increased ( $56.6 \%$ versus $40,4 \%$ boys, $p<0.001$ ). Thus, we found that among schoolchildren aged 7-10 and 11-14 years old, the total frequency of LHD + IDA increases $(43.9 \%$ and $53.1 \%, p \varphi<0.025)$ and this was due to an increase in IDA among girls at the age of 11-14 years (34.9\%) versus LVH $(23.3 \%, p \varphi<0.002)$.

When establishing the fact of anemization, as well as its severity, we based on the WHO recommendations (11, 182), according to which a decrease in the amount of hemoglobin below $120 \mathrm{~g} / \mathrm{I}$ in children over six years old is regarded as anemia, and in severity up to $90 \mathrm{~g} \mathrm{/} \mathrm{I} \mathrm{(mild} \mathrm{),} \mathrm{89-70}$ (moderate) and $\leq 69 \mathrm{~g} / \mathrm{I}$ as severe anemia. When analyzing our material in this direction, it was found that among schoolchildren there is predominantly mild - 165 (17.7\%) and moderately severe IDA - 67 (7.2\%, $p \varphi<0.012)$, and its III severity were not detected at all. In girls, the total frequency of I and II severity of IDA was doubled (32.5\% versus $17.4 \%$ in boys ( $p$ $<0.05)$.

Thus, the results of the epidemiological analysis of our material showed that among urban schoolchildren, hemoglobin health has deteriorated in recent years, among them the frequency of LHD has decreased, and IDA has increased. The latter is especially pronounced among girls aged 11-14 years. In this regard, as well as in order to comply with the requirements of population studies, we selected adolescent girls at the age of 12-14 years for prospective (long-term) observation and preventive therapy of ID, respectively with FLD (45), IDA I degree (56) and II degree of severity (25), which amounted to $88.2 \%$, $100 \%$ and $100 \%$ of the initial data.

The control group of schoolchildren consisted of 51 girls of the same age who did not have clinical and laboratory signs of ID, their share of the initial number of healthy girls 12-14 years old (77) was 66.2\%, which meets the requirements of the epidemiological analysis of the material (at least $50.0 \%$ from the original). These data are shown in Table 3.

As can be seen from the data in Table 3., we have observed the principle of equality in the management and treatment of sick children. The latter concerns the age aspect of the surveyed, as well as proportionality to the initial data.

To study the effectiveness of the preventive therapy of DZ using the Bioferron drug and to compare Ferrum-Lek (syrup) with it, we used the method of randomizing research numbers according to the principle of 1, 2, 3. that is, one child received the Bioferron drug $(A)$, the second Ferrum-Lek (B), and the third Bioferron + Ferrum-Lek (C), which is reflected in table 4. 
The American Journal of Medical Sciences and Pharmaceutical Research (ISSN - 2689-1026)

\section{Table 3}

Age composition of adolescent girls with iron deficiency

\begin{tabular}{|c|c|c|c|c|c|c|c|c|c|}
\hline \multirow{3}{*}{ № } & \multirow{3}{*}{ Group of surveyed } & \multicolumn{8}{|c|}{ Age of surveyed girls } \\
\hline & & \multicolumn{2}{|c|}{12} & \multicolumn{2}{|c|}{13} & \multicolumn{2}{|c|}{14} & \multicolumn{2}{|c|}{ total } \\
\hline & & abs & $\%$ & abs & $\%$ & abs & $\%$ & abs & $\%$ \\
\hline \multirow{3}{*}{1} & Teenage girls with IDA & 15 & 33,3 & 15 & 33,3 & 15 & 33,3 & 45 & 100 \\
\hline & IDA I stage & 16 & 28,6 & 20 & 35,7 & 20 & 35,7 & 56 & 100 \\
\hline & IDA II stage & 8 & 32,0 & 8 & 32,0 & 9 & 36,0 & 25 & 100 \\
\hline \multirow[t]{2}{*}{2} & Control group & 16 & 31,4 & 19 & 37,2 & 16 & 31,4 & 51 & 100 \\
\hline & Total & 55 & 31,1 & 62 & 35,0 & 60 & 33,9 & 177 & 100 \\
\hline
\end{tabular}

Table 4

Fragment of the method of exploratory randomization of the effectiveness of ferrotherapy in girls with LVH $(n=45)$

\begin{tabular}{|c|c|c|}
\hline $\begin{array}{c}\text { Row of random } \\
\text { numbers }\end{array}$ & $\begin{array}{c}\text { Serial number of surveyed girls with } \\
\text { LID }\end{array}$ & $\begin{array}{c}\text { Distribution of therapy } \\
\text { options }\end{array}$ \\
\hline 226 & 1 & A \\
\hline 316 & 2 & B \\
\hline 113 & 3 & C \\
\hline 991 & 4 & A \\
\hline 508 & 5 & B \\
\hline 860 & 6 etc. up to 45 C & C \\
\hline
\end{tabular}

The distribution of sick girls with ID, depending on the type of ferrotherapy, is shown in Table 5.

Table 5

Distribution of adolescent girls with ID according to from the type of iron preparation 
The American Journal of Medical Sciences and Pharmaceutical Research

(ISSN - 2689-1026)

Published: August 20, 2020 | Pages: $43-49$

Doi: https://doi.org/10.37547/TAJMSPR/Volume02Issue08-06

2020: 5.286

\begin{tabular}{|c|c|c|c|c|c|c|c|}
\hline \multirow{2}{*}{ № } & \multirow{2}{*}{ Name of the drug } & \multicolumn{2}{|c|}{ LID } & \multicolumn{2}{c|}{ IDA I stage } & \multicolumn{2}{c|}{ IDA II stage } \\
\cline { 2 - 8 } & abs & $\%$ & abs & $\%$ & abs & $\%$ \\
\hline 1 & Bioferron & 15 & 33,3 & 16 & 28,9 & 9 & 36,0 \\
\hline 2 & Ferrum-Lek & 15 & 33,3 & 20 & 35,7 & 8 & 32,0 \\
\hline 3 & $\begin{array}{c}\text { Bioferron } \\
\text { + Ferrum-Lek }\end{array}$ & 15 & 33,3 & 20 & 35,7 & 8 & 32,0 \\
\hline & Total & 45 & 100 & 56 & 100 & 25 & 100 \\
\hline
\end{tabular}

When prescribing ferro-drugs within each group, the principle of equality of age distribution was observed. For example adolescent girls who received Bioferron at the age of 12, 13, and 14 were divided into 5 cases, with a total of 15 children.

According to the conditions of the tasks of our work, the study of the antianemic properties of the vitamin-mineral complex Bioferron in syrup was carried out in comparison with the action of the iron-containing drug Ferrum-Lek in syrup, which is most often used in children's practice [].

The choice of the latter drug as the main antianemic drug was due to its good therapeutic effect and tolerability, the lack of components that impede the absorption of iron, and the iron in it is presented in the form of a hyperoxide polymaltase complex of ferric iron, and $5 \mathrm{mg}$ of syrup contains $50 \mathrm{mg}$ of iron []. A feature of this drug is also the fact that the entry of iron from the intestine into the blood occurs through active absorption, in contrast to salt compounds, the absorption of which occurs along the concentration gradient [] and at the same time the possibility of an overdose with an iron preparation is minimized []. ...
The herbal preparation Bioferron presented by us, produced by PE "Fito-Olam", is an extract of peripheral beets, wild rose, black raisins and barberry, each of which individually can have a therapeutic effect in case of anemia of a different nature. Complex Bioferron is a thick syrup of dark brown color, sweet taste with a pleasant odor, the consistency resembles liquid honey. The composition of Bioferron includes a complex of vitamins, minerals and carbohydrates from ecologically pure plant products of Uzbekistan: $1 \mathrm{ml}$ of syrup contains $5 \mathrm{mg}$ of iron, $3.46 \mathrm{mg}$ of vitamin C, $4.4 \mathrm{mg}$ of vitamin B2, $2.5 \mathrm{mg}$ of vitamin B12, i.e. That is, all of its components are involved in the formation of hemoglobin.

\section{CONCLUSIONS}

It follows from the above that Bioferron contains substances with known antianemic properties. At the same time, it is no less important for the patient that all the constituent parts of Bioferron are food products habitual for the diet of adults and older children, and it can be assumed that its intake in adolescent girls with ID is comfortable (compliance), has not only mild antianemic effect, but also has a tonic and tonic effect. A preliminary study of the Bioferron syrup (IHRV AN RUz, 2010) showed 
its high efficiency in experimental animals on the model of hemolytic and post-hemorrhagic anemia.

\section{ACKNOWLEDGMENT}

For the early diagnosis of IDA in adolescent girls, along with the use of conventional clinical, laboratory and biochemical studies of peripheral blood and iron metabolism, it is necessary to study the features of the somatic type of development, the direction of growth, harmony, features of sexual development and their deviations using schemes and indices.

The high efficiency of the drug "Bioferron" has been shown in primary prevention and therapeutic measures for the correction of IDA in adolescent girls aged 12-14 years. Positive dynamics and high digestibility of the drug "Bioferron" are most pronounced with mild degrees of iron deficiency (LDL, IRA grade I).

\section{REFERENCES}

1. Agzamov A.M., Niyazova M.T. Treatment of iron deficiency anemia in preschool children based on evidence-based medicine // Pediatrics.-2007.-No.1-2.-P.4446

2. Buglanov A.A., Turaev A.T., Makhmudova D.S., Hayitov B.A., Mamatkhanov D.A. Replacement therapy of iron deficiency with Ferrum-Lek preparations // Met.recommendations. - Tashkent, 2001.18 p.

3. Evtushchenko I.D., Sidorova M.M., Sotnikova L.S., Dygay A.M. The results of complex treatment of iron deficiency anemia in girls with uterine bleeding during puberty against the background of chronic opisthorchiasis // Siberian Medical Review. -2008.-№3.-P.34-37
4. Chulpanov I.R. Hygienic rationale for the use of special medicinal products for preschoolers suffering from iron deficiency anemia // Pathology. 1998.-№1 .-P.75-77Abou-Zeid A.H., Abdel-Fattah M.M., Shebri A.S. et all. Anemia and nutritional status of scoolchildren living at Saudi high altitud area //Saudi Med.J.2006.-V27.-№6.-P.862-869

5. Akarsu S., Kilic M., Yilmaz E. et all. Freguency of hipoferritinemia, iron deficiency and iron deficicency anemia in outpatients //Acta Haemetol.-2006.-V116. №1.-P.46-50

6. Kater S., Nuri Ozbek M., Yaramis A., Ecer S. Nutrirional magaloblastic anemia in young Turkish children in associeted with vitamin B12 deficiency and psychomotor retardetion //J.Pediatr.Hematol. Oncol.2006.-V.28.-No9.-P.59-562

7. Khien V., Odermatt P., Mel Y. et all. Anemia in a school of reural Combodja: detection, prevalence and links with intestinal worms and malnutririon //Bull.Soc.Pathol.Exot.-2006.-V.99.-№2.P.115-118

8. Ponca P. Cellular iron metabolism //Kidney int.Suppl.-1999.-V.69.-P.2-11

9. Quinto L., Aponte J.J., Sacarlal J. et all. Haemotological and biohemical indies in young African children: in scarch of reference intervels //Trop.med.Int Health.-2006.-V.11.-№11.-P.1741-1748

10. Qureshi N., Lubin B., Walters M.C. The preventation and management of stroke in sickle cell anemia //Expert.Opin.Biol.Ther.-2006.-V.6.-N№11.P.1087-1098 